\title{
O SUBLIME FERRABRÁS: O BAIXO EM UM SONETO DE BOCAGE
}

Giuliano Lellis Ito SANTOS

(Universidade de São Paulo)

giuito@usp.br

Resumo: $O$ artigo pretende analisar um soneto de cunho erótico-satírico de Manuel Maria de Barbosa Du Bocage com o objetivo de estabelecer as referências claras ao sentimento do sublime destacado por alguns filósofos contemporâneos ao poeta. A análise seguiu o poema verso a verso, buscando destacar os elementos mais consistentes para confirmar a hipótese de que o sublime figura como presença essencial no poema. As alusões ao falo e o efeito de sua visão aproximam-se de modo fundamental ao sublime apresentado pelos filósofos Immanuel Kant e Edmund Burke em obras consagradas como Observações sobre o sentimento do Belo e do Sublime e Uma investigação filosófica sobre a origem de nossa idéias do sublime e do belo. As reflexões desses pensadores trouxeram contribuição indiscutível para o aprofundamento na análise do soneto, que se configura um bom exemplo para a leitura da poesia bocageana.

Palavras-chave: Bocage. Sublime. Sátira. Priapo.

\section{THE SUBLIME FERRABRÁS: THE “LOW” IN A SONNET BY BOCAGE}

\begin{abstract}
This paper analyzes an erotic-satirical sonnet of Manuel Maria Barbosa Du Bocage, aiming to establish a sense of the sublime pointed out by some contemporary philosophers to the poet. The analysis followed the poem verse by verse, seeking to highlight the most consistent elements to confirm the hypothesis that the sublime figures as an essential presence in the poem. The allusions to the phallus and the effect of his vision are similar to the sublime presented by the philosophers Immanuel Kant and Edmund Burke in standard works such as Observations on the Feeling of the Beautiful and Sublime and A Philosophical Enquiry into the Origin of Our Ideas of the Sublime and Beautiful. The reflections of these thinkers brought indisputable contribution to deepening the analysis of the sonnet, which sets a good example for the reading of Bocage's poetry.
\end{abstract}

Keywords: Bocage. Sublime. Sátira. Priapo. 
Bocage, mais do que um poeta, significa um modo de se expressar. Ele se constitui como discurso pornográfico e jocoso, ligando-se muito mais à imagem delineada pelo anedotário sobre ele do que pela relação de unidade de sua obra.

Por sua vez, a obra do poeta é infinitamente maior do que as anedotas nos permitem vislumbrar, ou, como observa Cândido Martins, "é importante que o leitor fique, desde logo, com a ideia de que Bocage não é apenas autor de umas poucas dezenas de sonetos, mas de uma vasta obra volumosa e variada" (1999, p. 21). Também não podemos perder de vista que um dos meios que dá unidade à variedade de sua produção é a relação próxima com as poéticas clássicas. Portanto, o poeta trata "de empenhar seu engenho nas tópicas e ocasiões que o solicitavam, nem sempre igualmente toleradas pelo empirismo rijo da autoridade, mas sempre aplicando o decorum das poéticas classicizantes" (PÉCORA, 2001, p. 211).

Levando em conta as observações destacadas acima, pretendemos analisar um soneto de matéria erótico-burlesca, buscando compor a filiação dessa produção às poéticas clássicas e destacar sua reflexão sobre o conceito de sublime, recorrente em certa literatura da época.

Entendemos que o tratamento de matéria baixa dada no soneto "Êsse disforme, e rígido porraz" é representativo da imagem que envolve o poeta português, porém a reflexão subjacente sobre o sublime parece ocultada pela temática erótica. Portanto, concordamos com a conclusão de Pécora de que

[...] em torno de Bocage construiu-se uma imagem, culturalmente irresistível, de libertinagem. Mas seria entendê-la sobretudo como vocação poética virtuosística que pode desempenhar admiravelmente as tópicas sexuais em todos os modos e gêneros: da graça do falsamente ingênuo até o erótico da confissão íntima, passando pelo satírico da volúpia mais grosseira. O libertino bocageano, por aí, equivale à redescoberta intensa e enérgica das variedades da língua e de suas convenções letradas, numa sociedade ostensivamente monolítica, pobre de prazeres intelectuais, talvez mesmo "sem espírito" (2001, p. 245).

Dessa maneira, quando Bocage, dentro do decorum, escolhe uma temática baixa e dá-lhe tratamento baixo, respeitando as convenções letradas, temos simplesmente uma produção condizente com o exercício da poética clássica, porém a novidade pode entranhar-se no segundo plano do poema, que fica oculto pelo burlesco representado no primeiro.

Antes de passarmos ao soneto a ser analisado, precisamos ter em mente dois pontos que nos ajudam a entender a escolha do tema e sua forma de 
tratamento. Para isso, recorremos a uma poética precedente a Bocage, a Arte poética de Francisco José Freire, o Candido Lusitano, em sua segunda edição de 1759:

Dous modos pois, e dous meyos tem os bons Poetas, para fazerem bellas as luas compolições, ${ }^{1}$ e com ellas caufarem deleite. $\mathrm{O}$ primeiro he o de achar coulas, e verdades novas, eftranhas, e maravilholas, que per fi melmas caufem admiraçaõ. O legundo he o de pintar bem com vivas cores, e de ornar com pompa, novidade, e maravilholos artifícios as melmas verdades, que per fi mesmas naõ laõ admiráveis, nem eftranhas; e quem for dotado de huma, e outra virtude, póde feguramente dizer, que polfue, e fabe em que confiste a verdadeira belleza poética.

Segundo eftes principios podemos igualmente dividir em duas efpecies efta belleza poetica; ifto he, em materia, e em artificio. Ou o Poeta há de achar materia nova, admiravel, e eftranha; ou quando efta for trivial, reveftilla com artificio de novidade, e de cores maravilholas (1759, p. 58).

Nesse excerto podemos perceber que a novidade de um poema pode ser dada ou pela matéria, ou pelo artifício. Essa forma de se entender a criação poética recai sobre a limitação das tópicas poéticas a serem tratadas, mesmo que já possamos observar certa dilação dos temas, ou sobre o modo de manipular as formas poéticas convencionais.

Além desse procedimento tido como parte do trabalho poético, vale lembrar que as formas satíricas faziam parte das atividades corriqueiras das academias e os preceitos que regiam a forma de se compor em estilo baixo estavam definidos em alguns tratados dos séculos XVII e XVIII, como podemos notar num exemplo citado por Pécora, do "Tratado dos ridículos":

[...] não deves ter nojo de filosofar sobre Matérias nojentas para colher quase que da lama as gemas de uma Arte nobre; sendo o raio do Intelecto humano semelhante ao do Sol, que tem o privilégio de fluir sempre limpo por sobre as imundícies. Também a mente humana participa da Divina e com a mesma Divindade habita nos pântanos e nas estrelas: e do mais sórdido lodo, fabricou a mais Divina das Criaturas Corpóreas. (2001, p. 206)

Portanto, teríamos um caminho para lermos o soneto de Bocage:

1. A matéria baixa não deve ser desprezada simplesmente pela sua natureza;

2. O poeta precisa aplicar o decorum, ou seja, para a matéria baixa dar tratamento baixo.

\footnotetext{
${ }^{1}$ Optamos por representar com o símbolo r o fonema $\mathrm{S}$, acreditando que seja a transcrição mais
} fiel ao original. 
Sigamos, então, para a leitura completa do soneto a ser analisado:

\author{
Êsse disforme, e rígido porraz \\ Do semblante me faz perder a côr; \\ E assombrado d'espanto, e de terror \\ Dar mais de cinco passos para trás: \\ A espada do membrudo Ferrabrás \\ De certo não metia mais horror: \\ Êsse membro é capaz até de por \\ A amotinada Europa tôda em paz: \\ Creio que nas fodais recreações \\ Não te hão de a rija máquina sofrer \\ Os mais corridos, sórdidos cações: \\ De Vênus não desfrutas o prazer: \\ Que êsse monstro, que alojas nos calções \\ É porra de mostrar, não de foder (BOCAGE, 1969, p. 100).
}

Esse soneto caracteriza-se pela matéria baixa e pelo artifício baixo, colocando-se no campo da composição satírica, que causa o riso. A escolha do tema recai sobre a tópica clássica do deus-falo, Priapo, deus da fertilidade, que serve de motivo a uma série de poemas jocosamente obscenos, recolhidos em conjuntos de poemas nomeados priapeia. Além desse caráter obsceno, os poemas destinados a essa divindade "apresentam a dimensão religiosa do falo, a saber, símbolo de plenitude e exuberância procriadora em todas as esferas da vida, a vegetal, a animal e a humana" (OLIVA NETO, 2006, p. 11).

Ainda sobre Priapo, devemos destacar que em algumas histórias sobre 0 mito deparamo-nos com o impedimento do ato sexual, marca também presente na caracterização do Ferrabrás bocageano.

Contava-se que durante uma celebração dionisíaca Príapo viu a ninfa Lotis e apaixonou-se por ela; durante a noite ele tentou aproximar-se do lugar onde ela dormia, mas quando já estava perto da ninfa o asno de Sileno começou a relinchar, acordando Lotis e as Bacantes. Príapo desistiu de seus propósitos, e passou a aparecer ao lado de um asno.

$\mathrm{Na}$ tradição romana Príapo quis possuir Vesta, e quando ia violentá-la um asno começou a relinchar, despertando a deusa e livrando-a assim do impetuoso admirador (KURY, 2009, p. 400).

Podemos perceber que a composição de Bocage visa atualizar o mito, o qual será revivido através da figura de Ferrabrás. Porém, a matéria eróticosatírica é colocada em primeiro plano, deixando figurar em segundo plano o sentimento causado pela visão do falo. 
Retornando detidamente ao primeiro quarteto, somos apresentados, logo no primeiro verso, ao falo: "Êsse disforme, e rígido porraz". Características arquetípicas do deus Priapo. O primeiro termo utilizado para caracterizar o membro, "disforme", traz em sua morfologia a ausência de forma, a impossibilidade de delimitar e de medir. Tal propriedade aproxima-o do sentimento do sublime muito semelhante a explicação de Kant, em sua Crítica da faculdade do Juízo:

[...] denominamos algo grande, mas simplesmente, absolutamente e em todos os sentidos (acima de toda a comparação) grande, isto é, sublime, então se tem a imediata perspiciência de que não permitimos procurar para o mesmo nenhum padrão de medida adequado a ele fora dela, mas simplesmente nele (1995, p. 95).

Ser grande não garante em si o sentimento do sublime, pois lembrando uma breve observação de Longino: "o sublime é o eco da grandeza de alma" (1996, p. 54 , grifo no autor). Temos que o sublime não é valor intrínseco do objeto, mas sua projeção na grandeza na alma. Por isso, podemos supor que, para Bocage, "tratase então de produzir comoção mediante o traçado de cenas que se caracterizam tipicamente como sublimes, de acordo com leituras setecentistas de Longino" (PÉCORA, 2001, p. 218).

O estilo baixo escolhido pelo poeta garante a simplicidade da construção, que vai ajudar a compor o sublime, pois como destacado por Kant: "É necessário ao sublime ser sempre grande, o belo também pode ser pequeno. O sublime precisa ser simples, o belo pode ser adornado e amaneirado" (2014, s.p.).

A matéria escolhida para ser figurada no soneto faz parte tradição clássica da poesia obscena. Seu tratamento decoroso das convenções clássicas estão claras logo no primeiro verso, em que percebemos a matéria baixa e seu tratamento correlato. Por outro lado, o efeito causado pelo objeto imitado parece ser mais importante do que ele próprio:

Do semblante me faz perder a côr;

E assombrado d'espanto, e de terror

Dar mais de cinco passos para trás:

Ainda na apresentação da matéria do soneto, percebemos o sentimento do sublime. Neste ponto, notamos que a matéria escolhida desencadeia o terror. Com isso podemos supor que o soneto se estabelece com a existência de duas 
matérias: a primeira apresenta-se como a releitura do mito de Priapo e a segunda como o sentimento do sublime decorrente do terror suscitado pela observação do falo.

O terror é propriedade essencial para provocar o sentimento do sublime. Edmund Burke, contemporâneo de Bocage, aponta que

Tudo que seja de algum modo capaz de incitar as idéias de dor e de perigo, isto é, tudo que seja de alguma maneira terrível ou relacionado a objetos terríveis ou atua de um modo análogo ao terror constitui uma fonte do sublime, isto é, produz a mais forte emoção de que o espírito é capaz (1993, p. 48).

Esse o terror está pintado na face do eu lírico, que perde a cor, sente-se assombrado e afasta-se. Portanto, neste primeiro quarteto, ao que parece, passamos pelo potencial sublime de um objeto caracterizado pela sua falta de medida, sua magnitude, para o terror, representado pelos traços físicos do enunciador, e, por conseguinte, para sentimento do sublime.

Assim, depois da apresentação da matéria a ser tratada no soneto, podemos passar a sua conceituação no segundo quarteto.

A espada do membrudo Ferrabrás

De certo não metia mais horror:

Êsse membro é capaz até de por

A amotinada Europa tôda em paz:

O conceito vem em forma de comparação. Os dois primeiros versos trazem uma formação semelhante ao do primeiro quarteto, em que se dá a apresentação do objeto e o efeito de sua visão. No primeiro verso temos dois vocábulos que formam e exageram a imagem do falo, pois une a analogia bélica da espada com a caracterização metonímica do físico de Ferrabrás, ou seja, a palavra membrudo, que seguida pelo sufixo -udo, demonstra abundância, excesso e aumenta a característica do que se refere. No segundo verso apresenta-se o efeito, o sentimento de horror que o membro exagerado pode causar, a paralisação das revoltas, sugerindo o sentimento do sublime como mencionado por Kant: "ele [0 sentimento do sublime] é produzido pelo sentimento de uma momentânea inibição das forças vitais" (1996, p. 90).

O terror apresentado nos dois primeiros versos é caracterizado pela natureza do membro de Ferrabrás, que é superior ao terror particular das revoltas que ocorrem em toda a Europa. Nesse sentido, o segundo quarteto conceitua, 
através da comparação, a natureza de dois terrores: o que produz o sentimento do sublime e o produzido pela guerra. Ao diferenciá-los, o poeta delimita que o sentimento gerado pela técnica da guerra não produz o sublime, mas o medo. Por outro lado, o objeto, do qual seu poema tomou por matéria, pode produzir o efeito de paralisação, análogo ao sentimento do sublime.

O distanciamento entre dois terrores permite ao poeta definir melhor 0 sentimento do sublime, que passa pela valorização do artifício com que a poesia é criada, aproximando-se do fingimento, arraigado na imitação poética.

Podemos ler essa distinção no campo da poética, em que duas formulações nos auxiliam a entendê-la: a imitação Icástica e imitação Fantástica. A classificação é definida de forma mais apropriada pela Arte poética de Francisco José Freire:

A imitação Icaltica correfponde á imitação do particular, e tem por objecto todas as acções, e coulas, que procedem da natureza, ou da Arte, e naõ menos da Hiftoria, que da invençaõ de alguém. A [imitação] Fantaftica correfponde á imitação do univerlal, e tem por objecto tudo o que naõ exiftindo per fi, tem novo fer, e vida, nalcendo da fantalia do Poeta, quando entra a inventar novas coufas, ou acções limilhantes ás hiftorias, que le bem naõ luccederaõ, podiaõ fucceder (1759, p. 35).

A divisão entre imitação do particular e do universal visava separar a história, ligada ao real e a verdade, da poesia, ligada à verossimilhança, porém o próprio Freire propõe que a poesia pode fazer uso de ambas as imitações, "dizendo, que [a arte] admitte tanto huma, como a outra imitaçaõ" (1759, p. 38). Dessa maneira, pensando no soneto de Bocage, percebemos que a imitação fantástica predomina através da reelaboração do mito de Priapo e a icástica através ação prática que esse falo pode exercer.

De certo modo, a comparação é elemento essencial do segundo quarteto, porém a natureza das comparações define os elementos. Temos, portanto, a enunciação que marca o início da relação entre o falo e as revoltas: "metia mais horror".

O sublime provocado pela visão caricatural de Ferrabrás se contrapõe à tensão provocada pelas revoltas. Essa distinção ocorre não somente pelo efeito e natureza do terror causado, mas pela essencialidade de cada episódio. Desse modo, as revoltas se aproximam da imitação do particular, muito próximo à compreensão e juízo do homem. Por outro lado, o falo é apresentado como 
desmedida, uma imitação do universal, que faz eco na imensidão interior do homem através da incompreensão de suas fronteiras. Por isso, podemos aproximar o falo à criação poética que, envolta pela máscara do fingimento, se apoia na verossimilhança para representar a imensidão do universal.

Dando andamento à leitura do soneto, destacamos que no primeiro terceto apresenta-se o impedimento da prática sexual, como anotamos anteriormente com duas versões das narrativas ligadas ao mito de Priapo:

Creio que nas fodais recreações

Não te hão de a rija máquina sofrer

Os mais corridos, sórdidos cações:

Nesse momento, passamos do objeto e seu efeito para o uso; descemos do sentimento de terror que sugere o sublime para a prática do sexo pelo itifálico Ferrabrás. Nesse contexto, o poeta constata que não pode fazer uso de seu membro, pois até mesmo as prostitutas (cações) mais sujas e velhas fogem dele. O terror torna-se medo e deixa de produzir o sentimento do sublime, o particular esvazia o universal. Dessa maneira, a prática transforma o efeito, que agora se dá pela funcionalidade do objeto.

A distinção entre imaterial e material revela uma tensão entre a imitação e a ação. Nos versos do segundo quarteto, apresenta-se uma comparação em que o sentimento do sublime causado pela visão do membro disforme de Ferrabrás é capaz de paralisar a ação, as revoltas na Europa, já nos versos seguintes, do primeiro terceto, a ação se sobrepõe à arte, fazendo com que o objeto, produtor anteriormente do sentimento do sublime, seja visto como uma simples ameaça às prostitutas.

A forma de tratamento da matéria continua a mesma, porém muda-se o ponto de vista que o constrói. Dessa forma, nos quartetos o falo nos era apresentado da perspectiva artística, preocupada com o efeito produzido pela sua visão, nos tercetos ele constitui-se como objeto de uso prático, que, por seu tamanho, fica impossibilitado de ser utilizado.

Seguindo para a conclusão do soneto, lemos:

De Vênus não desfrutas o prazer:

Que êsse monstro, que alojas nos calções

É porra de mostrar, não de foder. 
A impossibilidade da prática sexual é reiterada no primeiro verso. No segundo verso retornamos para o campo do grotesco com a qualificação de monstro dada ao falo. Já no terceiro a conclusão esclarece sua função quando transformado em arte: mostrar.

O ultimo verso se encarrega de diferenciar a vida e sua prática da arte e sua imitação, portanto, olhamos para o poema como se este fosse o próprio falo de Ferrabrás, matéria imitada. Nesse sentido, podemos relembrar mais um trecho da Arte poética de Freire, em que se lê: "o fim da Poefia, em quanto Arte fabricante, he deleitar com a imitação" (1759, p. 55).

Portanto, se o fim da poesia é o deleitar com a matéria ou com o artifício "de dous modos póde fer efta Arte deleitável, ou com as coulas, e verdades, que ella imita, ou com a maneira de as imitar" (FREIRE, 1759, p. 55) -, os últimos versos do soneto explicitam a artificialidade de sua criação, expondo um objeto cuja função essencial não está ligada à sua função primeira, ou seja, o falo de Ferrabrás constrói-se como artefato artístico que deleita com a visão, porém não possui a finalidade prática de foder.

Retomando os elementos analisados do soneto, percebemos que a matéria escolhida possui relação com a tópica clássica e está inserida no campo da composição da poesia obscena ou erótico-satírica, portanto a releitura do mito de Priapo e sua colocação no espaço português de finais do século XVIII e início do XIX exige a manutenção do estilo baixo esperado para tal tema.

A matéria direciona o artifício, pois segue o princípio do decorum em que é essencial o equilíbrio entre a coisa a ser representada e a forma de tratamento que deve ser dada a ela. Dessa maneira, notamos a utilização de um léxico variado para designar o membro sexual masculino como porraz, espada, membro, monstro, máquina. Além disso, em alguns momentos percebemos o uso de palavras muito próximas ao dialeto popular como membrudo, fodais, cações, porra. Outro ponto que reforça a relação com o estilo baixo são as rimas, algumas delas feitas com o infinitivo do verbo como nos versos $10^{\circ}$ e $14^{\circ}$ em que as palavras sofrer e foder estão na posição de rima. Ainda podemos destacar a distorção para a composição do grotesco em que o falo é apresentado como disforme e monstruoso. 
O poema é uma máquina que constrói uma imagem sobre-humana, incita o terror sustentado pelo estilo baixo, pela simplicidade. Essa última característica apontada, nos remete a uma observação de Kant sobre o sublime em comparação ao belo clássico: "o sublime precisa ser simples, o belo pode ser adornado e amaneirado" (2014, s.p.). Portando, as palavras de Bocage definitivamente não buscam a produção do belo clássico, procuram, antes, representar o grotesco de forma simples, projetando uma reflexão sobre o efeito que este pode produzir em seu receptor.

Outra observação de Kant traz uma contribuição para compreendermos alguns elementos do soneto: "as coisas não naturais, na medida em que nelas se presume o sublime, embora encontrado em pouca ou nenhuma escala, são caricaturas" (2014, s.p.). Esse comentário leva-nos a refletir sobre o objetivo desta imitação, que, como sátira, projeta o riso, porém, em algum nível, trata do sentimento do sublime.

Essa tensão é sentida pela dupla recepção do objeto representado: o artificial e o prático. Entendemos como artificial o sentimento relacionado à abstração racional da arte. Essa condição permite ao poeta insinuar o sentimento do sublime em um objeto, que possui a capacidade de projetar um terror mais expressivo que o das revoltas. Com relação ao prático, entendemos como sendo a função natural do membro sexual, cujo ato não é permitida a Ferrabrás pela grandeza antinatural de seu falo.

As duas ideias ligadas ao falo, o sentimento do sublime e a função sexual, podem representar dois olhares sobre a arte. Podemos apontar que o primeiro visa uma condição ideal da arte, que deve engendrar, em seu receptor, sentimentos etéreos, sentimentos que permitam uma aproximação com 0 abstrato. Por outro lado, o segundo vê na arte somente o que ela pode ter de prático, entendendo que suas invenções não são passíveis de ação.

Bocage está inserido num momento em que a escrita seguia as convenções clássicas, porém por trás dessa convenção descortina-se uma racionalização sobre a produção e recepção da arte. As comparações presentes no soneto apontam para uma reflexão constante sobre o fazer poético, que busca novos meios de imitação. 
Ainda que o poeta português seja considerado principalmente clássico ,sua produção espraia-se pelo período nomeado pré-romantismo. A construção do baixo, com utilização do grotesco, na imagem de Ferrabrás segue as preceitos clássicos correntes no século XVIII, mesmo a inserção sub-reptícia do sentimento do sublime não permite considerá-lo um visionário. A discussão que apresenta figura como recolocação das convenções da poética clássica no horizonte da criação literária do final do século XVIII e início do XIX.

Portanto, o soneto analisado neste artigo representa um bom exemplo da utilização do estilo baixo como meio de reflexão de conceitos poéticos, pois o apelo de sua matéria, seja ela erótica, burlesca ou satírica, permite ao poeta disfarçar conceitos mais elaboradas que envolvem a produção da poesia.

\section{Referências bibliográficas}

MARTINS, J. Cândido. Para uma leitura de poesia de Bocage. Lisboa: Editorial Presença, 1999.

PÉCORA, Alcir. Parnaso de Bocage, Rei dos brejeiros. In: Máquina de gêneros. São Paulo: Edusp, 2001, pp. 203-245.

BOCAGE, Manuel Maria de Barbosa Du. Poesias, eróticas, burlescas e satíricas. São Paulo: Editôra Escriba, 1969.

FREIRE, Francisco Joseph. Arte poetica, ou regras da verdadeira poesia em geral, e de todas as luas elpecies principaes, tratadas com juizo critico. Lisboa: Offic. Patriarcal de Francilc. Luiz Ameno, 1759.

OLIVA NETO, João Ângelo. Falo no jardim: priapéia grega, priapeia latina. Cotia, SP: Ateliê Editorial; Campinas, SP: Editora da UNICAMP, 2006.

KURY, Mário da Gama. Dicionário de mitologia grega e romana. Rio de Janeiro: Zahar, 2009.

KANT, Immanuel. Crítica da faculdade do juízo. Rio de Janeiro: Forense Universitária, 1995.

LONGINO. Do sublime. São Paulo: Martins Fontes, 1996.

KANT, Immanuel. Observações sobre o sentimento do Belo e do Sublime: ensaio sobre as doenças mentais. Disponível em 
http://www.filosofia.com.br/figuras/livros_inteiros/170.txt. Acessado em 29 outubro 2014.

BURKE, Edmund. Uma investigação filosófica sobre a origem de nossa idéias do sublime e do belo. Campinas, SP: Papirus, 1993. 
Artigo recebido em: 11 de julho de 2014

Artigo aprovado em: 05 de setembro de 2014

\section{Sobre o autor:}

Giuliano Lellis Ito Santos possui graduação em Letras (Português/Russo) pela Universidade de São Paulo (2005). Possui Doutorado em Letras, na área de Literatura Portuguesa, pela Universidade de São Paulo (2011) com a tese $A$ ideia de história no último Eça, sob orientação da Profa. Dra. Aparecida de Fátima Bueno. Atualmente é professor substituto de Literatura Portuguesa na Universidade de São Paulo. Organizou em 2012 uma edição de $A$ cidade e as serras, de Eça de Queirós, pela Editora Babel. Além disso, publicou artigos relacionados ao estudo da obra de Eça de Queirós em revistas acadêmicas, entre eles "Os três Antônios: a recepção de Eça de Queirós na década de quarenta" (Convergência Lusíada), "A novela histórica de Gonçalo: escrita, publicação, recepção" (Via Atlântica), "Realismo e realidade: algumas proposições de Eça de Queirós" (Carandá). 